\title{
Rethinking research in breast-feeding: a critique of the evidence base identified in a systematic review of interventions to promote and support breast-feeding
}

\author{
M Renfrew ${ }^{1, *}$, H Spiby ${ }^{1}$, L D’Souza $^{1}$, LM Wallace ${ }^{2}$, L Dyson ${ }^{3}$ and F McCormick ${ }^{1}$ \\ ${ }^{1}$ Mother and Infant Research Unit, Department of Health Sciences, Area 4, Seebohm Rowntree Building, \\ University of York, Heslington, York YO10 5DD, UK: ${ }^{2}$ Health Services Research Centre, GE404, \\ Coventry University, Priory Street, Coventry CV1 5FB, UK: ${ }^{3}$ Nutritional Epidemiology Group, Faculty \\ of Medicine, Dentistry, Psychology and Health, University of Leeds, 30-32 Hyde Terrace, Leeds LS2 9LN, UK
}

Submitted 7 February 2006: Accepted 26 July 2006: First Published online 5 March 2007

\begin{abstract}
Objective: To appraise critically the relevance and value of the evidence base to promote and support the duration of breast-feeding, with a specific focus on disadvantaged groups.

Design: A systematic review was conducted of intervention studies relevant to enhancing the duration of breast-feeding; topics included public health, public policy, clinical issues, and education, training and practice change. A systematic search was conducted. Eighty studies met the inclusion criteria. Data were systematically extracted and analysed. Full results and recommendations are reported elsewhere. Here a critique of the evidence base - topics, quality and gaps - is reported.

Results: Many studies were substantially methodologically flawed, with problems including small sample sizes, inconsistent definitions of breast-feeding and lack of appropriate outcomes. Few were based on relevant theory. Only a small number of included studies (10\%) were conducted in the UK. Very few targeted disadvantaged subgroups of women. No studies of policy initiatives or of community interventions were identified. There were virtually no robust studies of interventions to prevent and treat common clinical problems, or of strategies related to women's health issues. Studies of health professional education and practice change were limited. Costeffectiveness studies were rare.

Conclusions: Policy goals both in the UK and internationally support exclusive breastfeeding until 6 months of age. The evidence base to enable women to continue to breast-feed needs to be strengthened to include robust evaluations of policies and practices related to breast-feeding; a step change is needed in the quality and quantity of research funded.
\end{abstract}

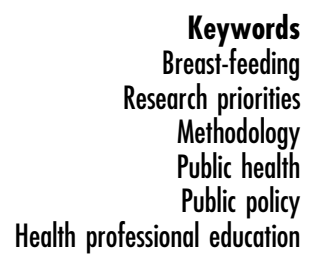

Breast-feeding has a fundamental role to play in improving public health ${ }^{1-3}$. Recent policy has at last recognised its importance; raising initiation rates is now a national target for the National Health Service (NHS) in England, and promoting exclusive breast-feeding until 6 months of age is a policy goal, in line with international recommendations $^{4-9}$.

Breast-feeding initiation rates in the UK are among the lowest in Europe, with rapid discontinuation and early supplementation among those who do start. Although initiation rates have been reported to have increased recently, they remain lower than in many other comparable countries ${ }^{10}$. Low initiation and continuation rates among low-income and other disadvantaged families $^{11}$ add to social inequalities in health outcomes and perpetuate the inter-generational cycle of poor health. The reasons for this dismal picture are multifaceted; they include the influences of society and cultural norms, unresolved clinical problems such as painful nipples and breast engorgement, the organisation of health services, and inadequate training of health professionals and other practitioners to support breast-feeding ${ }^{12}$. Important disincentives for continuing breast-feeding for 6 months in the UK are the limited monetary benefits of even the recently extended maternity leave and, linked with this, the culture of early return to work among low-income women. Overcoming these problems and enabling women to breast-feed will not be simple or straightforward.

Without appropriate strategies to address these problems, current policy targets are unlikely to be met. 
A systematic review was conducted recently to compile evidence of the effectiveness of interventions having an impact on the duration of breast-feeding, with a focus on what works for women from disadvantaged groups ${ }^{12}$. A wide range of studies of public health and clinical interventions and public policy were examined.

The aim of this report is to examine the evidence base identified during the course of the review with reference to the range of topics addressed in included studies; whether or not studies addressed the most appropriate/relevant questions; and whether relevant research is being conducted in the UK and internationally. Recommendations for future research are based on this analysis.

\section{Methods}

A systematic search was conducted on 13 relevant electronic databases (see Table 1 for a full list) and three journals were searched by hand (Journal of Human Lactation, Health Promotion International and Health Education and Behaviour). Full details of the comprehensive search strategy are given in the full report of the review $^{12}$. Table 2 lists the major areas covered, specific topics and their pre-specified inclusion criteria. The rationales for inclusion criteria for each subject area were underpinned by consideration of existing evidence from previous reviews in the topic area, the timing of major relevant NHS policies such as Health of the Nation $(1994)^{13}$ and Changing Childbirth (1993) ${ }^{14}$, existing knowledge of research in the field and relevance to the UK setting.

Studies for all except the clinical sections were included only if they had breast-feeding duration outcomes. For the clinical section, studies reporting outcomes related to problems likely to reduce breast-feeding duration (e.g.

Table 1 Databases searched

\begin{aligned} & \hline 1. ASSIA (Health subset) \\ & 2. British Nursing Index \\ & 3. CINAHL (Cumulative Index of Nursing Research \\ & and Allied Literature) \\ & The Cochrane Library Central \\ & 4. The Cochrane Pregnancy and Childbirth Group \\ & 5.$\quad$ Specialised Register of Controlled Trials \\ & 6. DHSS Data \\ & 7. Dissertation Abstracts \\ & 8. EMBASE \\ & 9. ERIC \\ & 10. HMIC \\ & 11. LILACS (Latin American and Caribbean Center \\ & 12. MEDLINE \\ & 13. NRR (National Research Register) \\ & 14. Psyclnfo \\ & 15. PsycLIT \\ & 16. Science Citation Index \\ & 17. Social Science Citation Index \\ & 18. Sociological abstracts \\ & 19. MIDIRS (all original articles) \\ & \hline\end{aligned}

nipple pain) were also included. For two topics, babyrelated problems and maternal problems that may affect breast-feeding, all designs including case studies were included, as it was known that there was very little, if any, research in these areas and material was needed to scope the problems and inform future research.

\section{Results}

Over 55000 citations resulted from the main electronic searches, and a further 8000 from handsearching and the smaller specialist databases. These were independently screened by two reviewers. This resulted in 940 citations for which full publications were sought. Each of these was subjected to a screening process to assess eligibility, again by two reviewers. As a result of this, 138 papers were identified for full data extraction. The whole team worked together on this process, to ensure appropriate allocation of papers to each of the 13 categories. As eligibility criteria varied between sections, decisions about exclusions varied between the sections. Fifty-eight ineligible papers were identified. Reasons for exclusion included: ineligible methodology (i.e. not a randomised controlled trial (RCT) in the sections which only included RCTs (36), no concurrent controls (one)); the study had a wider focus than breast-feeding (eight); no numerical breast-feeding outcomes were reported (seven); the paper was not available in our time frame (two); and ongoing studies with no results available (four). A total of 80 papers, including different aspects of one study reported in two different papers, and three systematic reviews met the criteria for the final review. This process is summarised in Fig. 1. Full data extraction tables are available in the final report ${ }^{12}$.

Table 3 summarises information about the topic area studied, the country in which the studies were conducted, dates of publication and whether or not studies examined disadvantaged groups.

Only 17 of the studies overall, and none of the public policy studies, examined disadvantaged women.

Only 10 of the studies were conducted in the UK. Of these, two were general interventions to offer support/care to women with new babies, and one was a case study of a single infant. Three RCTs studied a total of 832 mothers and babies, and four before/after studies included 3338 individual participants plus the 33 maternity units included in one Scottish study.

Only six studies in total addressed the specific problems of breast-fed babies such as sucking problems, jaundice, sleepy or crying babies, slow weight gain and tongue tie. All of these were small, five were simply descriptive and none were RCTs. We found no studies of antenatal care, or of maternal problems related to breast-feeding, that met the inclusion criteria.

Many of the studies screened for this review were methodologically flawed, and some were too small to be 
Table 2 Inclusion criteria for each section of the review

\begin{tabular}{|c|c|c|c|c|}
\hline Major area reviewed & Specific topic & Dates & Countries & $\begin{array}{l}\text { Research } \\
\text { designs }\end{array}$ \\
\hline \multirow[t]{5}{*}{ Public health } & $\begin{array}{l}\text { Support offered to pregnant and postpartum women by individuals and agencies } \\
\text { to increase the duration of breast-feeding, including peer and health professional support }\end{array}$ & 1990-June 2003 & Developed & RCTs \\
\hline & $\begin{array}{l}\text { Antenatal and postnatal classes/education intended to promote and support the } \\
\text { duration of breast-feeding (i.e. not general antenatal/postnatal classes) }\end{array}$ & 1990-June 2003 & Developed & RCTs \\
\hline & $\begin{array}{l}\text { Multifaceted programme-based social services interventions, including some } \\
\text { activities relevant to the promotion and support of breast-feeding duration, targeted } \\
\text { at specific, relevant groups including US WIC, Sure Start, Welfare Food Scheme, etc. }\end{array}$ & 1990- June 2003 & Developed & RCTs \\
\hline & $\begin{array}{l}\text { Interventions intended to promote and support breast-feeding duration targeted at } \\
\text { community groups, such as schools, media campaigns, etc. }\end{array}$ & 1990-June 2003 & Developed & $\begin{array}{l}\text { RCTs, controlled trials, } \\
\text { before/after studies }\end{array}$ \\
\hline & $\begin{array}{l}\text { Organisation of health care provision intended to promote and support } \\
\text { breast-feeding duration, including rooming-in, breast-feeding-only wards, etc. }\end{array}$ & 1990-June 2003 & Developed & $\begin{array}{l}\text { RCTs, controlled trials, } \\
\text { before/after studies }\end{array}$ \\
\hline Public policy & $\begin{array}{l}\text { Provision of maternity/paternity/parental leave, implementation of the WHO } \\
\text { code on the marketing of breastmilk substitutes, mother-friendly work policies, } \\
\text { the promotion of formula milk, and restriction of formula to prescription-only }\end{array}$ & 1990-June 2003 & Developed & $\begin{array}{l}\text { RCTs, controlled trials, } \\
\text { before/after studies }\end{array}$ \\
\hline \multirow[t]{6}{*}{ Clinical interventions } & $\begin{array}{l}\text { Antenatal practices, including antenatal expression of colostrum, } \\
\text { nipple preparation, and treatment for inverted and non-protractile nipples }\end{array}$ & 1995-June 2003 & All & RCTs \\
\hline & $\begin{array}{l}\text { Care in childbirth, including place of birth, continuity of care in labour, pain relief } \\
\text { in labour, interventions including induction, amniotomy, perineal care, food and } \\
\text { drink in labour, and mode of birth, where breast-feeding has been an } \\
\text { outcome measured }\end{array}$ & 1990-June 2003 & All & Systematic reviews \\
\hline & $\begin{array}{l}\text { Prevention of breast-feeding problems: including routines in care postpartum; skin to } \\
\text { skin contact, timing of the first feed, prevention of sore nipples including teaching } \\
\text { positioning and attachment to mothers, frequency and duration of breast-feeding, } \\
\text { supplementing the baby, use of weight and food charts, methods of giving additional } \\
\text { fluids, use of pacifiers }\end{array}$ & 1990-June 2003 & All & RCTs \\
\hline & $\begin{array}{l}\text { Treatment of breast-feeding problems, including sore nipples, infection, sore } \\
\text { breasts, engorgement, mastitis, breast abscess and insufficient milk, and the use } \\
\text { of interventions such as nipple shields, breast shells, dressings and applications }\end{array}$ & 1990-June 2003 & All & RCTs \\
\hline & $\begin{array}{l}\text { Baby-related problems including hypoglycaemia, jaundice, crying and colic, } \\
\text { sucking problems, sleep problems, sleepy babies, slow weight gain, Down's syndrome, } \\
\text { cleft lip and palate, tongue tie }\end{array}$ & 1990-June 2003 & All & All research studies \\
\hline & $\begin{array}{l}\text { Maternal problems that may affect breast-feeding including drug and substance abuse, } \\
\text { smoking, and maternal nutrition }\end{array}$ & 1990-June 2003 & All & All research studies \\
\hline $\begin{array}{l}\text { Health professional and } \\
\text { lay counsellor education, } \\
\text { training, and practice change }\end{array}$ & $\begin{array}{l}\text { Including the use of specific training programmes, ways of teaching positioning and } \\
\text { attachment to professionals, and ways of changing } \\
\text { professional practice. Only studies including the duration of breast-feeding as an } \\
\text { outcome included }\end{array}$ & 1980-June 2003 & Developed & $\begin{array}{l}\text { RCTs, controlled trials, } \\
\text { before/after studies }\end{array}$ \\
\hline
\end{tabular}




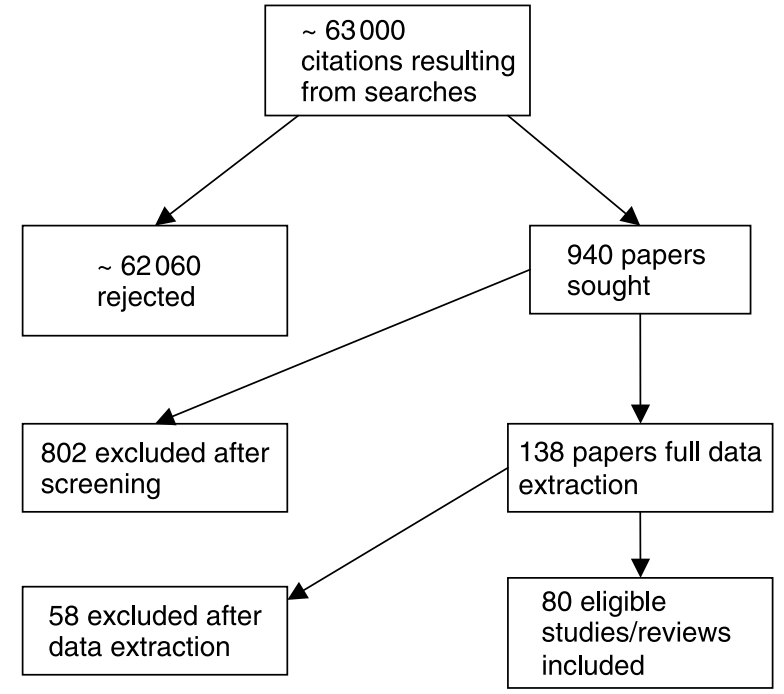

Fig. 1 Flowchart of the process of selecting the included papers

useful. The lack of rigour of even large-scale RCTs suggests a lack of attention to design. Over a quarter (14/51) of all RCTs $(n=51)$ included in the review had no clear inclusion and/or exclusion criteria, or these were not described at all. A priori sample size calculations were either not done or the rationale for calculations was unclear in over half of the RCTs (27/51). Blinded outcome assessment was either not adhered to or not described in over two-thirds (38/51) of trials. Only half $(25 / 51)$ of RCTs clearly demonstrated that analysis was by intention to treat.

There was a pervasive lack of understanding of the psycho-socio-biological nature of breast-feeding in the literature reviewed. Intervention studies rarely considered the effects of women's views and feelings, and the social and cultural context of breast-feeding; only seven intervention studies collected data on the views of recipients.

Studies did not address some key issues. Perhaps the largest and most important evidence gap was the lack of studies in areas where significant and recurrent problems continue to exist for breast-feeding mothers and babies; for example, studies of clinical interventions to address common problems such as 'insufficient milk', painful feeding and baby-related problems such as tongue tie/ankyloglossia, neonatal jaundice and inconsolable crying were missing from the literature. Only one-third of public health interventions targeted low-income women (12/37), where it is known that breast-feeding rates are lowest. Another gap in the literature related to intervention studies dealing with breast-feeding problems related to women's own health and lifestyle, such as smoking, use of prescription and non-prescription drugs, and breast surgery.

Few studies examined cost outcomes for families, health services, employers or others (5/79).

Very few studies were based on relevant theory, for example, of behaviour or organisational change. Assumptions were implicit but not articulated. This was especially notable in studies examining services and specific breast-feeding support interventions. Very few studies reflected contemporary philosophies and approaches to the organisation of care and policy such as woman- and family-centred care, keeping babies with their mothers whenever possible and treating woman as partners in care. Studies of educational interventions did not appear to be underpinned by approaches that treated health care professionals as adult learners; indeed no

Table 3 Summary of included studies

\begin{tabular}{|c|c|c|c|c|c|c|}
\hline Topic & $\begin{array}{l}\text { UK } \\
\text { studies }\end{array}$ & $\begin{array}{l}\text { Other } \\
\text { countries }\end{array}$ & $\begin{array}{c}\text { Studies targeting } \\
\text { disadvantaged groups }\end{array}$ & $1990-1995$ & Post-1995 & Total studies \\
\hline \multicolumn{7}{|l|}{ Section 1: public health interventions } \\
\hline Support & 3 & 8 & 3 & 2 & 9 & 11 \\
\hline Education & 0 & 9 & 4 & 3 & 6 & 9 \\
\hline Multifaceted & 0 & 9 & 4 & 5 & 4 & 9 \\
\hline Community-based & 0 & 0 & 0 & 0 & 0 & 0 \\
\hline Organisation of health care & 2 & 6 & 1 & 4 & 4 & 8 \\
\hline Subtotal & 5 & 32 & 12 & 14 & 23 & 37 \\
\hline \multicolumn{7}{|l|}{ Section 2: public policy interventions } \\
\hline Subtotal & 1 & 5 & 0 & 0 & 6 & 6 \\
\hline \multicolumn{7}{|l|}{ Section 3: clinical interventions } \\
\hline Antenatal care & 0 & 0 & 0 & 0 & 0 & 0 \\
\hline Care in childbirth* & 0 & 3 & 0 & 0 & 3 & 3 \\
\hline Prevention of problems & 0 & 13 & 0 & 0 & 13 & 13 \\
\hline Treatment of problems & 0 & 6 & 0 & 1 & 5 & 6 \\
\hline Baby-related problems & 1 & 5 & 0 & 0 & 6 & 6 \\
\hline Maternal problems that may affect breast-feeding & 0 & 0 & 0 & 0 & 0 & 0 \\
\hline Subtotal & 1 & 27 & 0 & 1 & 27 & 28 \\
\hline \multicolumn{7}{|c|}{ Section 4: health professional and lay counsellor education, training and practice change } \\
\hline Subtotal & 3 & 6 & 5 & 2 & 7 & 9 \\
\hline Total & 10 & 70 & 17 & 17 & 63 & 80 \\
\hline
\end{tabular}

* This section only included reviews, so data here are not comparable with other sections. 
educational models were identified in the studies reviewed.

Studies seldom described the full content of a complex intervention, and rarely defined 'control' care. The sketchy descriptions of the interventions were insufficient to replicate in research, or to implement in practice.

Specification of the sociodemographic characteristics of the participants was poor, and there was seldom any use of such information to investigate the differential effectiveness of interventions in diverse groups.

Very few (seven) intervention studies examined views and experiences of women or their families.

\section{Discussion}

Although intended to inform public health policy and practice in the UK, this review was based on a very wide search of the international literature. Each topic area had its own pre-specified criteria, based on an assessment of what was necessary for that specific area. The results shown here, therefore, are likely to be relevant to the duration of breast-feeding in developed country settings.

Each of the sections of the review had its own eligibility criteria, in recognition of the fact that different topics and questions require different research approaches; we wished to include material that was as relevant to policy and practice as possible. In six of the 13 review sections, only RCTs were included as these were considered to be the most appropriate design. In a further six sections, a range of study designs were included, recognising that in many areas of public health RCTs are complex, at times prohibitively expensive and, in some topics, simply inappropriate or impossible. In the section including only systematic reviews (care in childbirth), the limiting factor was resources; as this section was not central to the public health perspective of the review, this was conducted as a scoping exercise. Resources also did not allow inclusion of descriptive studies that might provide information about context to support decisions regarding policy and practice. Some of these studies have been included in a recent review of factors affecting breast-feeding ${ }^{15}$.

The volume of papers included - 77 primary studies and three reviews - might give the impression that there is ample evidence available to inform practice and policy. On the contrary, the most striking feature of this review is the paucity of findings from well-designed research to inform an important public health and policy issue. Even where studies had been conducted, details of interventions and processes were often scarce. Others have made similar observations in this ${ }^{12,16,17}$ and other areas of public health ${ }^{18}$.

The health outcomes related to infant feeding are extensive and expensive. The design and implementation of interventions to increase breast-feeding must be set against this ongoing expenditure, even though costs and savings do not necessarily come from the same budget nor are they controlled by the same commissioner. A comprehensive economic analysis of breast-feeding promotion and support is needed.

It is notable that in a field in which the behaviour and views of women, their families and society are so crucial, few studies incorporated an assessment of participants' views.

Finally, the lack of relevant research is a problem internationally, but it is a profound problem in the UK. Only seven breast-feeding-specific studies were conducted in the UK, indicating that the funding of research into ways of enabling women to breast-feed is not a research priority. A plethora of small, descriptive, often unfunded studies in this field, in contrast, indicates that it is a subject that is important to practitioners and to women. Funding awarded in the past 5 years by the Department of Health is an example of this: funding was given to support 79 small-scale, local projects, of which only one evaluation study $^{19}$ met the criteria for inclusion in our review. Although that initiative actively engaged practitioners, childbearing women and their families across the country, the lack of formal evaluation means that future service provision cannot with confidence be based on their experiences.

\section{Recommendations for future research}

- Key topics influencing breast-feeding need to become priorities for research funding in the UK. These are: impacts of health and welfare policies, mass media promotion and social marketing, interventions targeting subgroups of disadvantaged women, 'insufficient milk' syndrome, painful feeding, specific baby and maternal problems, the education and training of health professionals, and ways of changing practice.

- Newly designed interventions should be theory-based, and psychological models capable of describing why staff do not follow best practice should be used.

- Studies testing interventions related to breast-feeding duration need to be well designed and large enough to provide clear evidence.

- Intervention studies should include:

$\circ$ detailed information about the context and content of the intervention

- socio-economic details of participants

- appropriate outcomes, to include breast-feeding duration (consistently defined), costs, women's views of the content and process of the interventions and adequate length of follow-up.

- The evaluation of complex interventions, especially in health promotion, has been the subject of much debate $^{18,20,21}$. A recent paper $^{22}$ suggests a model that could address several of the problems in communitybased studies of complex interventions in breastfeeding, and further debate would be valuable. 
- Large-scale changes in health service organisation such as 'Patient Choice', managed care packages and integrated care pathways may well have an impact on breast-feeding when implemented in maternity settings. These would be suitable for large-scale studies across many sites, allowing simultaneous testing of system changes and differential impact on potentially vulnerable subgroups. In the UK, Health Equity Audit and health scrutiny by local councils ${ }^{23}$ both present an opportunity to explore how local organisational levers can be used to ensure the most disadvantaged are accessed and supported.

- Research is needed to compare policy interventions across different countries ${ }^{24}$, as well as research within health care systems to establish the most promising means of integrating action across sectors and between government and front line services.

Sadly, this study adds to the existing evidence that current policy related to community-based initiatives is not always based in evidence ${ }^{25}$. To address the profound evidence gaps identified so that current policy and practice goals can be met, breast-feeding needs to become a priority for a range of research funding bodies. A step change is needed in both the quantity and the quality of work funded. A problem-based approach, in which new research is funded based on an assessment of the issues, and of the problems faced by women and by practitioners, is essential.

\section{Acknowledgements}

We are grateful to Dr Caroline Mulvihill, National Institute for Health and Clinical Excellence (with the Health Development Agency at the time the review was undertaken), who acted as second reader for some included papers in the original review, and Dr Mike Woolridge, University of Leeds, who commented on aspects of the clinical interventions section in the original review. An Advisory Group commented on aspects of the original review; they included Phyll Buchanan, Christine Carson, Janet Fyle, Caroline Healy, Krystyna Henderson, Sally Inch, Mike Kelly, Jane Putsey, Felicity Savage, Amanda Sowden and Tricia Younger. We received helpful comments from two anonymous peer reviewers. The work was funded by the Health Development Agency, England.

\section{References}

1 Standing Committee on Nutrition of the British Paediatric Association. Is breast-feeding beneficial in the UK? Archives of Disease in Childhood 1994; 71: 376-80.

2 Quigley MA, Cumberland P, Cowden JM, Rodrigues LC. How protective is breast-feeding against diarrhoeal disease in infants in 1990s England? A case control study. Archives of Disease in Childhood 2006; 91: 245-50.

3 Faculty of Public Health Medicine. Promoting Breast-feeding (Guidelines). Guidelines for Health Promotion Number 41.
London: Royal Colleges of Physicians of the United Kingdom, Faculty of Public Health Medicine, 1995.

4 Department of Health. Health Inequalities: National Targets on Infant Mortality and Life Expectancy. Technical Briefing. London: The Stationery Office, 2002. Also available at http://www.dh.gov.uk/assetRoot/04/07/78/96/04077896.pdf

5 Department of Health. Priorities and Planning Framework 2003-2006. London: Department of Health, 2003.

6 Department of Health. National Standards, Local Action: Health and Social Care Standards and Planning Framework 2005/6-2007/8. London: The Stationery Office, 2004. Also available at http://www.dh.gov.uk/PublicationsAndStatistics/Publications/PublicationsPolicyAndGuidance/PublicationsPAmpGBrowsableDocument/fs/en?CONTENT_ID $=4096173 \&$ chk $=$ V8WLUg

7 Department of Health. Maternity Standards, National Service Framework for Children, Young People and Maternity Services. London: The Stationery Office, 2004. Also available at http://www.dh.gov.uk/assetRoot/04/09/05/23/04090523.pdf

8 Department of Health. Choosing Health: Making Health Choices Easier. London: The Stationery Office, 2004. Also available at http://www.dh.gov.uk/PublicationsAndStatistics/Publications/PublicationsPolicyAndGuidance/PublicationsPolicyAndGuidanceArticle/fs/en?CONTENT_ID $=4094550 \&$ chk $=$ aN5Cor

9 World Health Organization (WHO). Infant and Young Child Nutrition; Global Strategy for Infant and Young Child Feeding. Geneva: WHO, 2003. Also available at http://www.who.int/nutrition/publications/gs_infant_feeding_text_eng.pdf

10 Bolling K. Infant Feeding 2005: Early Results. London: The Information Centre, Government Statistical Service, UK Health Departments, 2006.

11 Hamlyn B, Brooker S, Oleinikova K, Wands S. Infant feeding 2000. A survey conducted on behalf of the Department of Health, Social Services and Public Safety in Northern Ireland. London: The Stationery Office, 2002. Also available at http://www.dh.gov.uk/assetRoot/04/05/97/63/04059763.pdf

12 Renfrew MJ, Wallance L, Dyson L, D'Souza L, McCormick FM, Spiby H. The effectiveness of Public Health Interventions to Promote the Duration of Breast-feeding: Systematic Review of the Evidence. London: National Institute for Health and Clinical Excellence, 2005. Also available at http://www.publichealth.nice.org.uk/page.aspx?o=511622

13 Department of Health. The Health of the Nation. London: HMSO, 1991.

14 Department of Health. Changing Childbirth. London: HMSO, 1993.

15 Chambers J, McInnes R. Psychosocial Factors Associated with Breast-feeding: A Review of Breast-feeding Publications 1990-2005. Edinburgh: NHS Health Scotland, 2006.

16 Guise JM, Palda V, Westhoff C, Chan BKS, Helfand M, Lieu TA. The effectiveness of primary care based interventions to promote breast-feeding: systematic evidence review and meta-analysis for the US preventative task force. Annals of Family Medicine 2003; 1: 70-8.

17 Protheroe L, Dyson L, Renfrew MJ, Bull J, Mulvihill C. The Effectiveness of Public Health Interventions to Promote the Initiation of Breast-feeding: Evidence Briefing. London Health Development Agency, 2003.

18 Oakley A, Strange V, Bonell C, Allen E, Stephenson J. Process evaluation in randomised controlled trials of complex interventions. British Medical Journal 2006; 332: 413-6.

19 Winterburn S, Jiwa M, Thompson J. Maternal grandmothers and support for breast-feeding. Journal of Community Nursing 2003; 17: 4-9.

20 Nutbeam D. Evaluating health promotion - progress, problems and solutions. Health Promotion International 1998; 13: 27-44. 
21 Medical Research Council (MRC). A Framework for the Development and Evaluation of Randomised Controlled Trials for Complex Interventions to Improve Health. London: MRC, 2000. Also available at http://www.mrc.ac.uk/pdfmrc_cpr.pdf

22 Hawes P, Shiell A, Riley T. Complex interventions: how 'out of control' can a randomised trial be? British Medical Journal 2004; 328: 1561-3.

23 Birmingham City Council Scrutiny Report. Children's Nutrition - Mothers Who Wish to Breast-feed. A Pilot Health Scrutiny Review. Birmingham: Birmingham City Council, 2003. Also available at http://www.birmingham.gov.uk/Media/Children's\%20Nutrition\%20Report.pdf?MEDIA_ID=139105\&FILENAME=Children's\%20Nutrition\%20Report.pdf

24 European Commission. Protection, Promotion and Support of Breast-feeding in Europe: A Blueprint for Action. Italy: European Union with IRCCS, 2004. Also availbale at http://new.wales.gov.uk/docrepos/40382/dhss/403821218/ eu-blueprint-w.pdf?lang $=\mathrm{cy}$

25 Coote A, Allen J, Woodhead D. Finding Out What Works: Understanding Complex Community-based Initiatives. London: King's Fund, 2004. 